Preprint of paper: S.A. Rocks, D. Wang, D. Sun, S.N. Jayasinghe, M.J. Edirisinghe, R.A. Dorey, Direct writing of lead zirconate titanate piezoelectric structures by electrohydrodynamic atomisation, J.Electroceramics, 19, 287-293, 2007

\title{
Direct Writing of Lead Zirconate Titanate Piezoelectric Structures by Electrohydrodynamic Atomisation
}

\author{
S.A. Rocks ${ }^{1}$, D. Wang ${ }^{2}$, D. Sun ${ }^{3}$, S.N. Jayasinghe ${ }^{3}$, M.J. Edirisinghe ${ }^{3}$, R.A. Dorey ${ }^{1}$. \\ ${ }^{1}$ Nanotechnology Centre, Cranfield University, Bedfordshire, UK, ${ }^{2}$ Materials \\ Department, Queen Mary, University of London, London, UK, and ${ }^{3}$ Mechanical \\ Engineering Department, University College, London, UK. \\ s.rocks@cranfield.ac.uk
}

Direct writing, consisting of the directed deposition of individual droplets of ceramic suspension using ink jet printing can be used to produce piezoelectric structures with feature sizes in excess of $100 \mu \mathrm{m}$. This work presents an alternative direct writing technique, consisting of directed individual droplets produced by electrohydrodynamic atomisation (EHDA), where feature sizes an order of magnitude smaller can be achieved. This technique opens up the possibility of using direct writing technology to produce integrated MEMS devices. Low toxicity lead zirconate titantate (PZT) sol has been used in conjunction with the EHDA process to produce isolated features and lines with dimensions as small as $20 \mu \mathrm{m}$. These features, when fired, form the perovskite PZT crystal structure. Using an X-Y stage to move the sample, it is possible to create a variety of structures.

Keywords: 3D structures, direct printing, PZT, electrohydrodynamic, EHDA

\section{Introduction}

Lead zirconate titanate (PZT) ceramics are well known ferroelectric materials, which can be used in piezoelectric, electro-optic and pyroelectric devices [1]. Nanostructured PZT can exhibit different ferroelectric properties compared to PZT structures formed of larger particles [2] and can be used in a wide range of applications [3].

Both lift off and mask and etch techniques, coupled with sol gel processing or sputtering, are used to fabricate thin ceramic structures for use in microelectromechanical systems (MEMS). As the thickness of the required features increases, mask and etch techniques are more favoured due to the increased difficulty in achieving effective lift off.

These methods are capable of achieving high resolutions [4-6] - especially for thin structures - but require long processing times, fabrication of photolithographic masks, numerous process steps and a large degree of waste of material. Direct writing of ceramic structures, consisting of directed droplets of a sol or suspension, is presently receiving considerable interest with ink jet deposition of ceramics [7] and polymer [8] films as it would eliminate many of these issues. The most common approach is to use ink jet printing. However, to produce fine features it is necessary to deposit small droplets. This is compounded due to the spreading of the droplet following impact with the substrate [9]. In the case of commonly used piezo-head driven printing, this approach is limited by the size of the nozzle compared to the printed structures, as the droplet and relic size are closely related to the internal diameter of the nozzle [10]. Typically the droplets generated are between 1.5 and 2 times the nozzle diameter. Therefore, to get small droplets, a finer nozzle is required making the passage of concentrated particulate suspensions extremely difficult and the deposition of droplet 
Preprint of paper: S.A. Rocks, D. Wang, D. Sun, S.N. Jayasinghe, M.J. Edirisinghe, R.A. Dorey, Direct writing of lead zirconate titanate piezoelectric structures by electrohydrodynamic atomisation, J.Electroceramics, 19, 289-293, 2007

relics less than $100 \mu \mathrm{m}$ in size virtually impossible. Smaller nozzles can be used with more dilute suspension, however, the degree of spreading then increases [9]. Controlled drying of large droplet relics [11] has been used to produce small droplets ( $20 \mu \mathrm{m}$ diameter), however, there is a large associated shrinkage which limits the resolution of this technique as each droplet must be isolated from it's neighbour. In contrast, electrohydrodynamic atomization (EHDA) uses larger nozzles of several hundred micrometers in diameter and generates droplet relics less than $50 \mu \mathrm{m}$ in size. EHDA is fast becoming an important route for the preparation of fine ceramic powders [12] as well as thick [13] and thin films [14].

The electrohydrodynamic process consists of a nozzle, or needle, and a ground electrode between which a voltage is applied. A solution or suspension flows through the needle at a controlled rate. The surface of the solution or suspension is subjected to an electrical stress and deforms into an elongated jet. This jet subsequently detaches from the body of liquid and disintegrates into fine droplets [15]. The geometry of the jet and droplet generation can be classified into different spray modes, as discussed by Jaworek and Krupa [16]. The break-up of the stable cone-jet mode can be regulated to generate fine uniform droplets, the deposition of which can be controlled to print structures.

In this work, we have used EHDA deposition to make ceramic features formed of multiple layers of a propanol-based PZT sol. The PZT features have been studied before and after sintering. The deposition of the features is directed by the use of an $\mathrm{X}-\mathrm{Y}$ stage which has a resolution of $2.5 \mu \mathrm{m}$ [17].

\section{Experimental Procedure}

PZT sol was prepared from the precursors lead acetate, titanium isopropoxide and zirconium propoxide. Titanium isopropoxide was added to zirconium propoxide prior to the addition of the solvents 1-propanol and glacial acetic acid. An excess of lead acetate was then added to the solution and the system was then refluxed at a low heat for 30 minutes. The final chemical stoichiometric ratio of the PZT sol was adjusted to be $\mathrm{Pb}$ 1.10: $\mathrm{Zr} \mathrm{0.48:} \mathrm{Ti} \mathrm{0.52.} \mathrm{The} \mathrm{sol} \mathrm{concentration} \mathrm{was} \mathrm{then} \mathrm{altered} \mathrm{to} 0.6,0.3,0.2$ and $0.1 \mathrm{M}$ concentrations using 1-propanol and acetic acid in a 1.1:1 ratio.

The PZT sol density was obtained by measuring the mass of a known volume of sol. The viscosity was calculated using a U-tube viscometer (SC/542.20, Schott Instruments GmbH, Germany). The surface tension was measured using the Du Nouy ring method (Tensionmeter K9, Kruss GmbH, Germany). A conductivity probe (Hi 8733, HANNA Ltd., UK) was used to estimate the sol conductivity. All measurements were calibrated using ethanol. The particle size of the PZT sol was measured using photon correlation spectroscopy (PCS) on a Malvern Zetasizer 3000 Instrument (Malvern Instruments, UK) with an external laser (wavelength $=488 \mathrm{~nm}$; power ranges from $10 \mathrm{~mW}$ to $50 \mathrm{~mW}$ ).

To determine the optimal sintering conditions for PZT sol, thin films were spin coated onto platinum-coated silicon wafers (University Wafers, Massachusetts, USA) and sintered at temperatures between $600^{\circ} \mathrm{C}$ and $800^{\circ} \mathrm{C}$ for $0,10,20$ and 60 minutes. The 
Preprint of paper: S.A. Rocks, D. Wang, D. Sun, S.N. Jayasinghe, M.J. Edirisinghe, R.A. Dorey, Direct writing of lead zirconate titanate piezoelectric structures by electrohydrodynamic atomisation, J.Electroceramics, 19, 289-293, 2007

crystal structure of the PZT sol after sintering was determined using X-ray diffraction (XRD; Siemens D5005 X-ray Diffractometer; Siemens Ltd., UK).

The equipment and procedure used is described in previous work [18]. The printing apparatus consisted of a Harvard PHD 4400 programmable syringe pump (Harvard Apparatus Ltd., Edenbridge, UK), a nozzle (0.33 x $0.64 \mathrm{~mm}$ aperture) and a point ground electrode both connected to a high voltage power supply (Glassman FC30, Glassman Europe Ltd., Tadley, UK) capable of supplying up to $30 \mathrm{kV}$, as shown in Figure 1. A ring ground electrode was used in place of the point ground electrode in initial studies to determine whether the experimental system would allow the formation of a stable cone-jet using the PZT sol. The liquid flow rate was varied between $8.3 \times 10^{-11} \mathrm{~m}^{3} \mathrm{~s}^{-1}$ and $5.7 \times 10^{-11} \mathrm{~m}^{3} \mathrm{~s}^{-1}$ and the applied voltage was varied between $4.3 \mathrm{kV}$ and $4.5 \mathrm{kV}$. Separate droplets were printed with a distance of $5 \mathrm{~mm}$ between the ground electrode and substrate and $1 \mathrm{~mm}$ between the nozzle and the substrate. Lines were printed with a distance of $1 \mathrm{~mm}$ maintained between the ground electrode and substrate and between the nozzle and the substrate. An X-Y stage (Micromech Ltd., Essex, UK) was used to move the substrate and control the feature deposition. The substrates used were quartz slides (Sigma Aldrich Chemical Company, Dorset, UK) and platinum-coated silicon wafers (University Wafers, Massachusetts, USA). The printed line width can be varied by increasing the flow rate of the sol or by increasing the distance between the nozzle and the substrate.

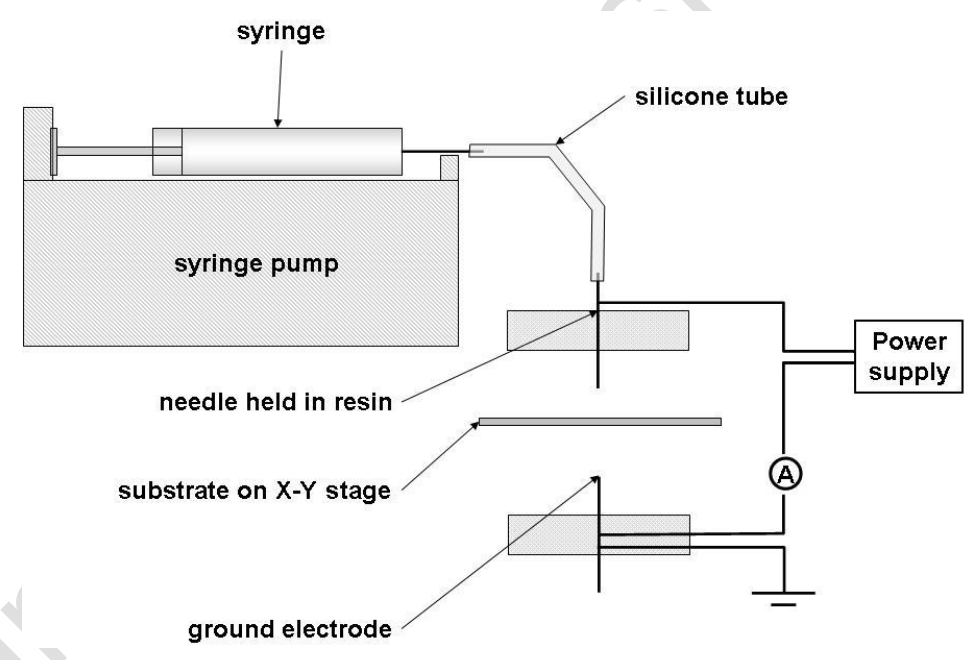

Fig. 1. Schematic representation of electrohydrodynamic atomisation apparatus for the creation of ceramic features.

The surface profile of the deposited features was determined using a Veeco DEKTAK Surface Profiler (Veeco Instruments Incorporated, UK). An environmental scanning electron microscope (ESEM; Philips XL30 ESEM, Philips Electronics UK Ltd., UK) was used to investigate the microstructure of the deposited features.

Single-layered PZT features were formed by depositing thin lines adjacent to one another. Multi-layered PZT features were deposited by printing multiple lines on top of one another. Features made from multiple layers were dried at $200^{\circ} \mathrm{C}$ for one minute and then at $350^{\circ} \mathrm{C}$ for $30 \mathrm{~s}$. The $\mathrm{X}-\mathrm{Y}$ stage was used to move the deposition 
Preprint of paper: S.A. Rocks, D. Wang, D. Sun, S.N. Jayasinghe, M.J. Edirisinghe, R.A. Dorey, Direct writing of lead zirconate titanate piezoelectric structures by electrohydrodynamic atomisation, J.Electroceramics, 19, 289-293, 2007

area and was controlled by Motion Planner software (Microsoft based freeware) as described in previous publications [17].

The electrical properties of the printed structures were determined by depositing gold electrodes by evaporation( $2 \mathrm{~mm}$ and $1 \mathrm{~mm}$ in diameter) and measuring the conductivity and dielectric loss at $1 \mathrm{kHz}$ using a Precision Component Analyser 6425 (Wayne Kerr Ltd., UK).

\section{Results and Discussions}

\subsection{Sol properties}

The properties of the PZT sol $(0.6 \mathrm{M})$ are given in Table 1. The propanol-based PZT sol has density and viscosity values within the same order of magnitude as those of its solvents; the density of acetic acid and 1-propanol is $1049 \mathrm{Kg} \mathrm{m}^{-3}$ and $800 \mathrm{Kg} \mathrm{m}^{-3}$, respectively, whereas the $\mathrm{PZT}$ sol is $1081 \mathrm{Kg} \mathrm{m}^{-3}$; the viscosity of acetic acid and 1propanol is $1.13 \mathrm{mPa} \mathrm{s}$ and $2.3 \mathrm{mPa}$, respectively, whereas it is $4.4 \mathrm{mPa}$ s for the PZT sol,. The mean particle size of the PZT sol was $12.6 \mathrm{~nm}$.

Table 1. Chemical properties of propanol-based PZT sol (0.6 M).

\begin{tabular}{|c|c|c|c|c|c|}
\hline & $\begin{array}{l}\text { Density } \\
\left(\mathrm{Kg} \mathrm{m}^{-3}\right)\end{array}$ & $\begin{array}{c}\text { Viscosity } \\
\text { (mPa s) }\end{array}$ & $\begin{array}{c}\text { Surface } \\
\text { tension } \\
\left(\mathrm{mN} \mathrm{m^{-1 } )}\right.\end{array}$ & $\begin{array}{c}\text { Particle Size } \\
\text { [mean } \\
\text { (standard } \\
\text { deviation)] } \\
\text { (nm) }\end{array}$ & $\begin{array}{l}\text { DC Elec trical } \\
\text { Cond uc tirity } \\
\left(\mathrm{S} \mathrm{m}^{2}\right)\end{array}$ \\
\hline $\begin{array}{l}\text { Propanol } \\
\text { PZT }\end{array}$ & 1081 & 4.4 & 26 & $12.6(6.56)$ & $4.4 \times 10^{-3}$ \\
\hline 1-propanol & 800 & 2.3 & $23.8^{1}$ & - & - \\
\hline Acetic acid & 1049 & $1.1 \mathrm{~s}$ & 27.6 & - & - \\
\hline
\end{tabular}

The electrical conductivity of the propanol-based PZT sol used for these experiments is much higher than that of other suspensions used in previous EHDA studies [18], where alumina ink with ethanol solvent had an electrical conductivity of $0.043 \mathrm{mS} \mathrm{m}^{-}$ 1. Due to the high electrical conductivity, the charged particles will be attracted to the ground electrode in the apparatus (Figure 1). The attraction between the particles and ground electrode will provide a greater degree of control of deposition of the PZT droplets. 
Preprint of paper: S.A. Rocks, D. Wang, D. Sun, S.N. Jayasinghe, M.J. Edirisinghe, R.A. Dorey, Direct writing of lead zirconate titanate piezoelectric structures by electrohydrodynamic atomisation, J.Electroceramics, 19, 289-293, 2007

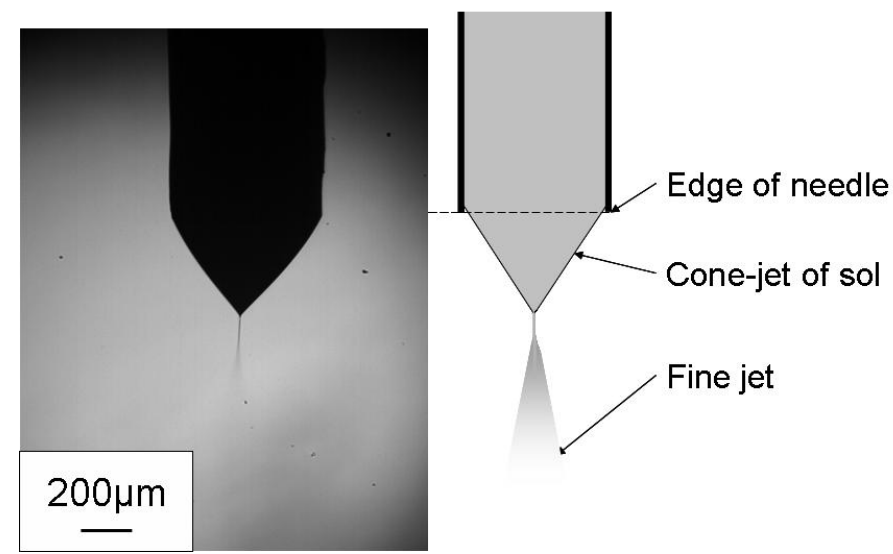

Fig. 2. High speed camera photograph and schematic of stable cone-jet of PZT sol formed using the EHDA technique.

A stable cone-jet of propanol-based PZT was formed using the EHDA apparatus (as shown in Figure 1) with a ring ground electrode instead of a point ground electrode (Figure 2). The ring electrode was $10 \mathrm{~cm}$ below the edge of the needle. The PZT sol was passed through at a flow rate of $5.7 \times 10^{-11} \mathrm{~m}^{-3} \mathrm{~s}^{-1}$ and the applied voltage was 4.5 $\mathrm{kV}$. The stability of the formed cone-jet will allow a consistent rate and size of droplets to be produced and deposited.

To determine the optimal sintering conditions, the propanol-based PZT sol was spin coated onto platinum-coated silicon wafers and then subjected to a range of sintering temperatures and durations. Figure 3 shows the results of samples sintered at $650^{\circ} \mathrm{C}$ for different times.

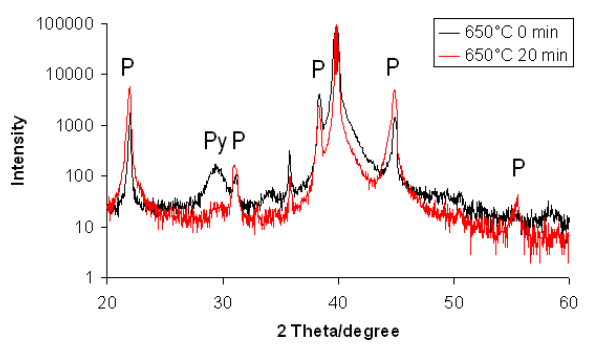

Fig. 3. XRD pattern of propanol-based PZT sol sintered at $650^{\circ} \mathrm{C}$ for 0 and 20 minutes. The pyrochlore $(\mathrm{Py})$ and perovskite $(\mathrm{P})$ phases are indicated.

The XRD traces (Figure 3) indicate that the pyrochlore phase is prevalent in the samples sintered for less than 20 minutes. When the sintering time is increased, the pyrochlore phase decreases and the perovskite phase becomes more prominent. The optimal temperature was determined by the comparison of the XRD pattern. Samples sintered at $750^{\circ} \mathrm{C}$ for 0 minutes had pyrochlore peaks in the XRD pattern, however these were shown to decrease after 20 minutes. The intensity of the pyrochlore peak did not decrease with longer sintering times. Samples sintered at $600^{\circ} \mathrm{C}$ still showed the pyrochlore peak after sintering for 30 minutes. The lowest temperature where there was a low incidence of the pyrochlore phase compared to the perovskite phase was $650^{\circ} \mathrm{C}$. Therefore the optimal sintering temperature and time for the propanolbased PZT sol used in these experiments was $650^{\circ} \mathrm{C}$ for 20 minutes. The sintering conditions used for the remainder of the experiments were $650^{\circ} \mathrm{C}$ for 20 minutes, ramping up at $2^{\circ} \mathrm{C}$ per minute. 
Preprint of paper: S.A. Rocks, D. Wang, D. Sun, S.N. Jayasinghe, M.J. Edirisinghe, R.A. Dorey, Direct writing of lead zirconate titanate piezoelectric structures by electrohydrodynamic atomisation, J.Electroceramics, 19, 289-293, 2007

The determination of the sintering durations below 20 minutes show relatively large amounts of an intermediate pyrochlore phase [19,20], which is not piezoelectric. At 20 minutes a small amount of pyrochlore is present with a larger proportion of the desired perovskite phase present as well. With longer sintering durations and higher temperatures, the pyrochlore phases starts to become more noticeable as lead is lost from the PZT structure. Due to the increased surface area of the printed PZT structures, the possibility of loss of chemicals from the surface of the ceramic is increased. Therefore, the sintering conditions are set at a low temperature for a short time to minimise this loss.

\subsection{Printed droplets}

PZT droplets were printed using the EHDA apparatus (Figure 2) with a point ground electrode. The nozzle was $5 \mathrm{~mm}$ above the glass substrate and the ground electrode was $1 \mathrm{~mm}$ below the substrate. It was possible to vary the size of the droplets (Figure $4 \mathrm{a}$ and $\mathrm{b}$ ) with a minimum droplet size of $10 \mu \mathrm{m}$ (Figure $4 \mathrm{~b}$ ). The deposited droplets have the appearance of a dimpled mound. Due to the nature of the sol-gel system it is unclear whether such dimples are due to impact spreading, differential gelling of the sol, shrinkage, or the Marangoni effect (where mass is transferred in a liquid due to surface tension differences). The fact that the features are evident prior to drying indicates that it is most likely a combination of impact spreading and gelling. The printed PZT droplets remain intact during sintering (Figure $4 \mathrm{c}$ ).
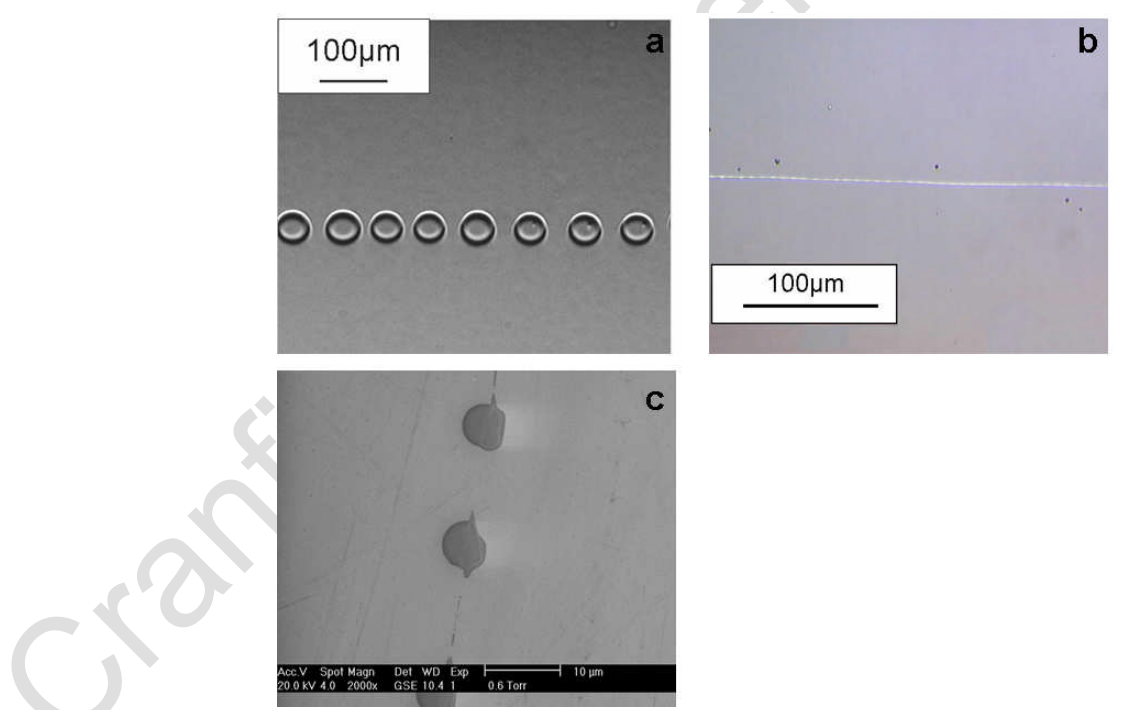

Fig. 4. Droplets of 0.6 M PZT printed using EHDA are shown before sintering (a and b) and after sintering at $650^{\circ} \mathrm{C}$ for 20 minutes (c). The printed droplets are a) $50 \mu \mathrm{m}$, b) $10 \mu \mathrm{m}$ and c) $5 \mu \mathrm{m}$ in diameter. 
Preprint of paper: S.A. Rocks, D. Wang, D. Sun, S.N. Jayasinghe, M.J. Edirisinghe, R.A. Dorey, Direct writing of lead zirconate titanate piezoelectric structures by electrohydrodynamic atomisation, J.Electroceramics, 19, 289-293, 2007
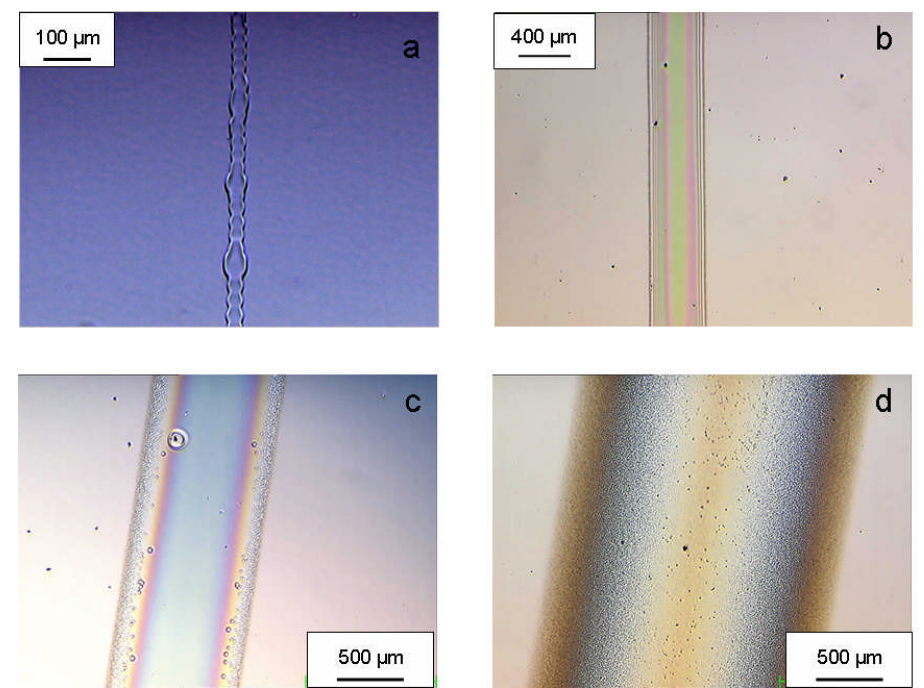

Fig. 5. EHDA deposition of 0.6M PZT sol into lines of differing widths. At narrow widths $(\mathrm{a} ; 50 \mu \mathrm{m})$ the formation of the line from adjacent droplets is noticeable. At larger widths $(b ; 400 \mu \mathrm{m})$, the lines are smooth-walled. After a certain line width the film deposition decreases in quality (c), until there is no continuous film present (d).

Lines were printed using the EHDA technique from droplets deposited so that they overlap (Figure $5 \mathrm{a}$ ). The printing parameters (flow rate and distance between nozzle and wafer) can then be altered to vary the line width (Figures $5 \mathrm{~b}, \mathrm{c}$ and d). As the line width is increased, the printed structure becomes less continuous and the definition at the edge of the line is decreased (Figures $5 \mathrm{c}$ and $\mathrm{d}$ ). The surface profile of a cross section of the printed line was investigated (Figure 6).

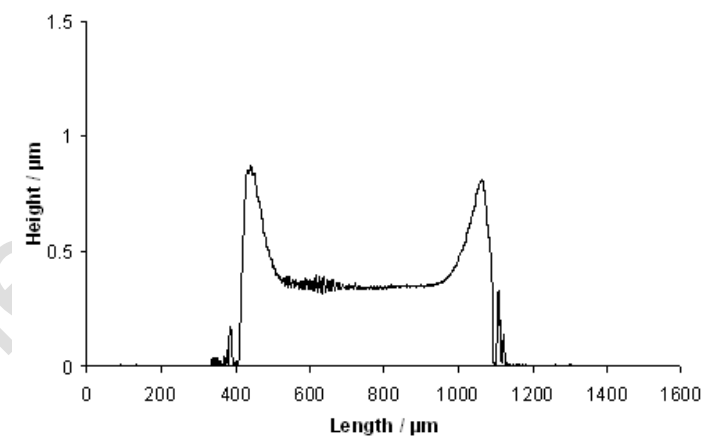

Fig. 6. Surface profile of an unsintered PZT line printed using 0.6M PZT sol and electrohydrodynamic atomisation.

The surface profile of a representative continuous line (line width $700 \mu \mathrm{m}$ ) is shown in Figure 6. The surface profile of the line shows a characteristic trough shape. This is representative of all the lines printed using this technique. The trough-like crosssection is thought to be due to the impact of the droplets on the wafer surface and the drying characteristics of the PZT sol.

Lu and colleagues [13] have previously used EHDA to deposit PZT thick films which have markedly different microstructures when compared to the PZT features produced in this work. Previously, we [21] have also shown that different microstructures of ceramic films produced by EHDA when compared to printed structures. These 
Preprint of paper: S.A. Rocks, D. Wang, D. Sun, S.N. Jayasinghe, M.J. Edirisinghe, R.A. Dorey, Direct writing of lead zirconate titanate piezoelectric structures by electrohydrodynamic atomisation, J.Electroceramics, 19, 289-293, 2007

observations suggest that the sequential directed impact of droplets, due to the point ground electrode, limits the available drying time enabling a smooth line to be formed. However the trough-like surface profile (Figure 6) indicates that the force of impact of the droplet leads to the spreading of the sol on the substrate. The raised edge at the periphery is due to the surface tension forces that limit the spread and radial flow of the line [13].

The line spreading on droplet impact can then be applied to the surface profile of squares formed by printing lines adjacent to one another. The width of the raised edges indicates that the trough formation of each line is maintained and that the edges of two adjacent lines combine to form one wider raised edge.

\subsection{Printed squares}

Two dimensional features were formed by printing single lines adjacent to one another using the stepper function of the X-Y stage. Single layered features were initially printed to determine the correct sol concentration for printing (Figure 7).
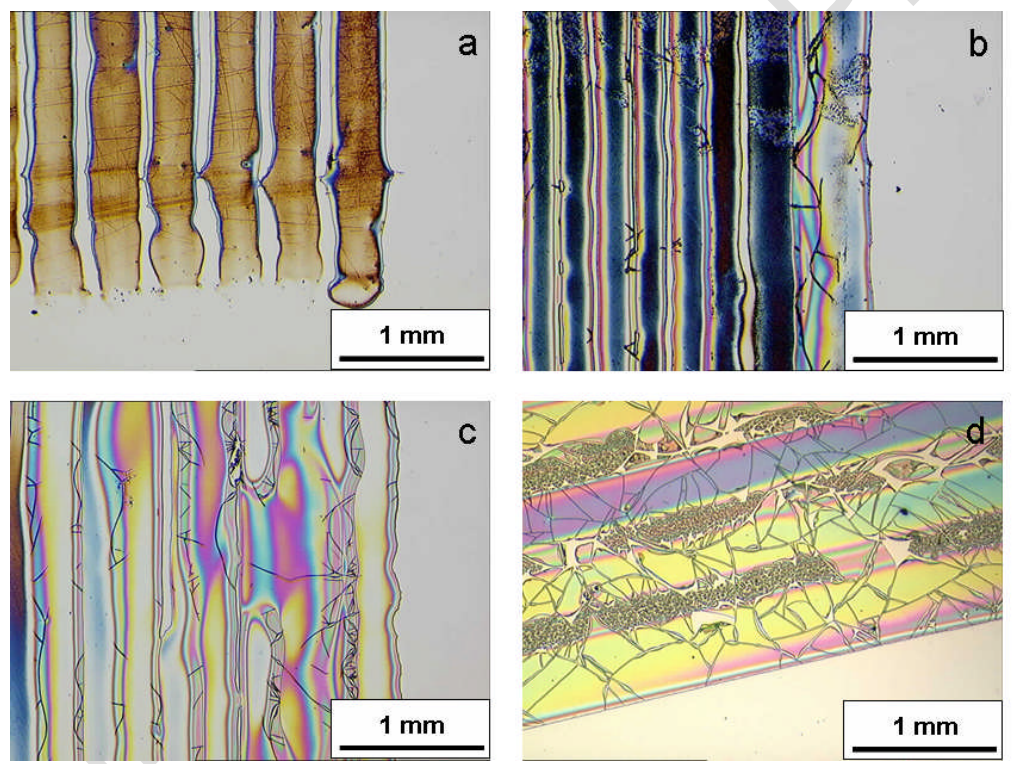

Fig. 7. PZT features printed by EHDA using a) $0.1 \mathrm{M}$, b) $0.2 \mathrm{M} \mathrm{c)} 0.3 \mathrm{M}$ and d) $0.6 \mathrm{M}$

PZT sol after sintering at $650^{\circ} \mathrm{C}$ for 20 minutes. The lines visible on the $0.1 \mathrm{M}$ sample are continuous through several adjacent lines and are therefore thought to be due to scratches on the surface of the Pt coated wafer.

The lack of cracking after sintering in the lines printed using the $0.1 \mathrm{M} \mathrm{PZT}$ sol (Figure 7 a) compared to the other concentrations investigated (Figure $7 \mathrm{~b}$, a and d) suggests that it is the most suitable concentration for printing structures using the EHDA technique. The thicknesses of the printed features were shown to increase as the concentration of the PZT sol increased. The $0.1 \mathrm{M}$ PZT feature was $100 \mathrm{~nm}$ thick, the $0.2 \mathrm{M}$ PZT feature was $200 \mathrm{~nm}$ thick, the $0.3 \mathrm{M}$ feature was $300 \mathrm{~nm}$ thick and the $0.6 \mathrm{M}$ PZT feature was $500 \mathrm{~nm}$ thick (average values).

Cracking of the PZT lines after sintering (Figure 7) is probably due to the increased stresses due to shrinkage. The cracks appear to originate at the edge of the structure, 
Preprint of paper: S.A. Rocks, D. Wang, D. Sun, S.N. Jayasinghe, M.J. Edirisinghe, R.A. Dorey, Direct writing of lead zirconate titanate piezoelectric structures by electrohydrodynamic atomisation, J.Electroceramics, 19, 289-293, 2007

which has been shown to be the thickest part of the structure. Therefore it is likely that the thickness of the edge of the film is the cause of the cracking.

The single lines can be printed repeatedly on top of each other to build-up a multilayered structure. This is possible due to the degree of control of the wafer placement with the X-Y stage used for these experiments. Multi-layered PZT features are thicker than single layered features suggesting that the printed ceramic structure has dried in between the printed layers and that the subsequent layers are deposited on top of the original layer (Figure 8). The average thickness of one layer is $100 \mathrm{~nm}$ whilst the average thickness of three layers is $250 \mathrm{~nm}$. This suggests that there is a small degree of redissolution.

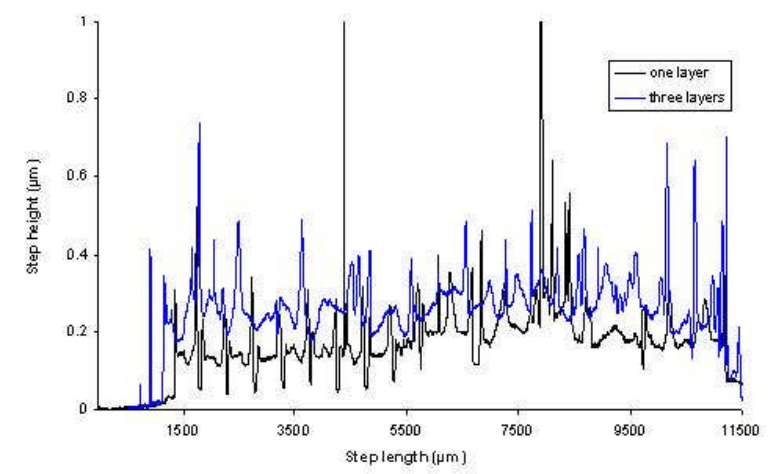

Fig. 8. Surface profile of a $10 \mathrm{~mm} \times 10 \mathrm{~mm}$ PZT square printed using $0.1 \mathrm{M}$ PZT made from one and three layers of 20 lines. The average height of one layer is 185 $\mathrm{nm}$, whilst the average height of the three layered feature is $272 \mathrm{~nm}$.

It was found that there was conduction between the top and bottom electrodes through the PZT film when tested using a Wayne Kerr Precision Component Analyser. It is thought that this is due to micro-holes present within the sintered structures. It may be possible to overcome this when the direction of the printed lines in adjacent layers are printed at $90^{\circ}$ to one another forming a cross hatched structure.

\section{Conclusions}

Electrohydrodynamic spray deposition of ceramic structures is a useful direct writing technique that can be used to deposit perovskite PZT features. The technique is very adaptable and has a good printing resolution. Thicker features can be printed using multiple layers or by increasing the concentration of the PZT sol used. The optimal concentration for printing $10 \mathrm{~mm}$ x $10 \mathrm{~mm}$ squares of multiple layers was determined to be $0.1 \mathrm{M}$. The optimal sintering conditions for these features were determined to be $650^{\circ} \mathrm{C}$ for 20 minutes, which minimises the loss of lead from the increased surface area of the structures.

\section{Acknowledgments}

This work is part-funded by the EPSRC as part of an Engineering Functional Materials Exploratory Project (grant number EP/C51940). Dr. R. Dorey is supported by a Royal Academy of Engineering/EPSRC Research Fellowship.

\section{References}


Preprint of paper: S.A. Rocks, D. Wang, D. Sun, S.N. Jayasinghe, M.J. Edirisinghe, R.A. Dorey, Direct writing of lead zirconate titanate piezoelectric structures by electrohydrodynamic atomisation, J.Electroceramics, 19, 289-293, 2007

1. A. Wu, P.M. Vilarinho, I.M. Salvado, A.L. Kholkin, J.L. Baptista, Brit. Ceram. Proc. 63, 155-162 (2003).

2. S. Choi, J. Heo, D. Kim, I. Chung, Thin Solid Films 464-465, 277-281 (2004).

3. APC international Ltd., Piezoelectric ceramics: principle and applications, (2002).

4. U.P. Schonhölzer, N. Stutzmann, T.A. Tervoort, P. Smith, L.J. Gaucker, J.Am.Ceram.Soc, 85, [7], 1885-1887 (2002).

5. C.R. Martin, I.A. Aksay, J.Electroceram, 12, 53-68 (2004).

6. J. Baborowski, J.Electrocerm, 12, 33-51 (2004).

7. X. Ding, Y. Li, D. Wang, Q. Yin, Ceram. Int. 30, 1885-1887 (2004).

8. E. Tekin, B-J. de Gans, U.S. Schubert, J. Mat. Chem. 14, 2627-2632 (2004).

9. J.A. Lewis, Current Opinion in Solid State and Materials Science, 6, 245-250 (2002).

10. R. Naguera, M. Lejeune, T. Chartier, J. Eur. Ceram. Soc. 25, 2055-2059 (2005).

11. J. Park, J. Moon, H. Shin, D. Wang, M. Park, Journal of Colloid and Interface Science, 298, 713-719 (2006).

12. S.N. Jayasinghe, R.A. Dorey, M.J. Edirisinghe, Z.B. Luklinska, Appl. Phys. A 80, 723-725 (2005).

13. J. Lu, J. Chen, W. Huang, Z. Ping, Sensors and Actuators A. 108, 2-6 (2003).

14. H. Huang, X. Yao, X.Q. Wu, M.Q. Wang, L.Y. Zhang, Thin Solid Films 458, 7176 (2004).

15. R.P.A. Hartman, J.-P. Borra, D.J. Brunner, J.C.M. Marijnissen, B. Scarlett. J. Electrostat. 47, 143-170 (1999).

16. A. Jaworek, A. Krupa, Experiments in Fluids 27, 43-52 (1999).

17. S.N. Jayasinghe, M.J. Edirisinghe, Appl. Phys. A. 80, 399-404 (2005).

18. S.N. Jayasinghe, M.J. Edirisinghe, J. Euro. Ceram. Soc. 24, 2203-2213 (2004).

19. J. Reading, S. Gordeev, M.T. Weller, J. Mater. Chem. 12, 646 (2002).

20. V.S. Tiwari, A. Kumar, V.K. Wadhawan. J. Mater. Res. 13, 2170 (1998).

21. D. Sun, S.A. Rocks, M.J. Edirisinghe, R.A. Dorey, Y. Wang, J. Nanosci.

Nanotech. 5, 1-6 (2005). 